\title{
What Makes Complex Systems Complex?
}

\author{
Russ Abbott \\ Department of Computer Science, California State University \\ russ.abbott@gmail.com
}

\begin{abstract}
This paper explores some of the factors that make complex systems complex. We first examine the history of complex systems. It was Aristotle's insight that how elements are joined together helps determine the properties of the resulting whole. We find (a) that scientific reductionism does not provide a sufficient explanation; (b) that to understand complex systems, one must identify and trace energy flows; and (c) that disproportionate causality, including global tipping points, are all around us. Disproportionate causality results from the wide availability of energy stores. We discuss three categories of emergent phenomena-static, dynamic, and adaptive-and recommend retiring the term emergent, except perhaps as a synonym for creative. Finally, we find that virtually all communication is stigmergic.
\end{abstract}

Keywords: complex systems, reductionism, energy flows, tipping points, emergence

\section{In Memoriam}

David Pines, co-founder of the Santa Fe Institute, passed away May 3, 2018. An obituary on the Santa Fe Institute website (2018a) describes him as follows.

Pines was a longtime advocate for describing the properties of systems that arise from the behaviors of their underlying components in terms of "emergence."

He is best known for his contributions to understanding the phenomena that emerge from the complex interactions of the elementary constituents of matter.

Although I never met him, the numerous warm and admiring remembrances make it clear that Professor Pines made significant contributions to many fields; his founding and continuing support of the Santa Fe Institute was just one of them. One can get a sense of him as a person from a lecture he gave a year and a half before his death (Pines, 2016). 
In his honor, this paper includes a number of extracts from his work about emergence. I don't agree with everything he said, but I want to offer an additional minor platform for his voice.

\title{
¿Qué hace que los sistemas complejos sean complejos?
}

\begin{abstract}
RESUMEN
Este documento explora algunos de los factores para hacer que los sistemas complejos sean complejos. Primero examinamos la historia de los sistemas complejos. Según Aristóteles, la forma en que se unen los elementos ayuda a determinar las propiedades del todo resultante. Encontramos (a) que el reduccionismo científico no proporciona una explicación suficiente; (b) que para comprender sistemas complejos, uno debe identificar y rastrear los flujos de energía; y (c) esa causalidad desproporcionada, incluidos los puntos de inflexión a nivel mundial, nos rodean. La causalidad desproporcionada resulta de la amplia disponibilidad de tiendas de energía. Discutimos tres categorías de fenómenos emergentes-estáticos, dinámicos $y$ adaptativos-y recomendamos retirar el término emergente, excepto tal vez como sinónimo de creativo. Finalmente, encontramos que prácticamente todas las comunicaciones son estigmáticas.
\end{abstract}

Palabras clave: sistemas complejos, reduccionismo, flujos de energía, puntos de inflexión, emergencia

\section{是什么让复杂系统变得复杂？}

\section{摘要}

本文探索了一些使复杂系统变得复杂的因素。笔者首先检验 了复杂系统的历史。亚里士多德认为, 各种因素的结合方 式帮助确定了起决定作用的因素的性质。笔者发现, (a) 科学还原论没有提供一个充足的解释; (b) 为理解复杂系 统, 则必须识别并追踪能量流; (c) 不成比例的因果关 
系, 包括全球临界点, 都围绕在人们身边。不成比例的因果 关系是由能量储存的广泛可获得性所导致的。笔者探讨了突 发现象的三种类型——静态、动态和适应, 并提出淘汰 “突 发” 这一术语, 转而用创造性代替。笔者结论发现，几乎一 切沟通都具有共识主动性（ stigmergic）。

关键词: 复杂系统, 还原论, 能量流, 临界点, 突现

\section{Introduction}

$\mathrm{N}$ early three and a half decades after the founding of the Santa Fe Institute-year zero for the modern study of complex systemsthere is still no widely accepted definition of what a complex system is. Yet interest in the field continues, as evidenced by the titles both of this journal and of the conference from which the papers in this edition sprang. This paper continues the exploration of what makes complex systems complex. It begins with a brief history of complex systems-in Section 2-and then examines three broad categories of factors that contribute to complexity. Section 3 examines disproportionate causalitythe phenomenon that a spark can start a fire. Examples include global (e.g., climate) tipping points, control systems, switches, symbolic causes, and the prerequisite to it all, available energy. Section 4 returns to what seems like a wellworn area: emergence. It proposes three fairly clean-cut subcategories of emergence, static, dynamic, and adaptive, and concludes that adaptive emergence is a synonym for the creative process. Section 5 suggests that stigmergy char- acterizes nearly all communication. That section highlights the inevitable material traces associated with communication. Section 6 looks back over the paper and offers a summary.

\section{A Brief History of the Idea of Complex Systems}

Quite a few steps were required to flesh out the idea of a complex system.

\subsection{Aristotle}

Aristotle took one of the earliest. In the Metaphysics (350 BCE), he asked what it is about an integrated "whole," what we might call a system, that distinguishes it from a pile of its parts. His answer was that a whole consists of both matter and design, which he calls form. He said that the way a whole's components are organized and joined together contributes both to its properties and to its persistence as a unified entity. Over the years, this has been compressed to the whole is more than the sum of its partsi.e., structure and design matter.

Was this a new insight? Wheels with axels were known for five millennia prior to Aristotle (see Gasser, 2003). Wheels with axels certainly incorporate 
design features. And they have properties their components lack individually. So the principle that design matters was known-at least intuitively-long before Aristotle. Yet, an explosion of Greek technology occurred in the century after Aristotle. Did Aristotle help trigger it? I know of no research on that question.

\subsection{Science, Reductionism, and Anti-Reductionism}

One can trace the birth of modern science, and with it reductionism, to the mid-sixteenth century. By the mid-seventeenth century, Hooke (1665) expected the microscope to show us "all the secret workings of Nature [managed as if] by Wheels, and Engines, and Springs." Soon afterwards, Fontenelle (1686) expressed the common view that "the universe is like a watch, only bigger." Yet he was skeptical (see letters, 1766) that the clockwork universe metaphor extended to biology.

Suppose animals are machines. When you put Monsieur Dog Machine and Mlle. Dog Machine together, soon you have little Puppy Machines. But two Watches might lie together all their lives without ever producing a puppy watch.

By the mid-nineteenth century, Mill (1843, Bk. III, Ch.6, \$1) was more direct.

The phenomena of life bear no analogy to any of the effects produced by the components of the body considered as physical agents. No mere summing up of the separate actions of its elements will ever amount to the action of the living body itself.

\subsection{British Emergentists}

In the early twentieth century, British emergentists postulated that the world

is divided into discrete strata arranged in order of increasing ... complexity. Fundamental physics is the base level, followed by chemistry, biology, and psychology (and possibly sociology). To each level corresponds a special science, whose task is to elucidate [the laws of] that level. -O’Connor (2015)

In other words, nature builds upwards by developing coherent and internally consistent levels.

The emergentists picture of a multi-layered world is more relevant than they imagined. Computational systems are indeed developed along these lines. The lowest level consists of programs written in the language of the bare computer. Operating systems, e.g., Window, Unix, MacOS, and higher level programming languages follow until we reach user applications.

Modern technology also fits the emergentist mold. The cell phone incorporates devices that depend on an enormous number of technologies.

A flaw in the emergentist vision is that the levels are not a strict hierarchy. For example, the bacterium Ideonella sakaiensis lives on Polyethylene tere- 
phthalate (PET), the primary material used in the manufacture of single-use plastic beverage bottles (Yoshida et al., 2016).

\subsection{General System ${ }^{1}$ Theory, Autopoiesis, and Dissipative Structures}

Schrödinger (1944) and then Von Bertalanffy (1968) added another insight: the importance of open systems and the importation of energy.

In What is life (1944) Schrödinger wrote the following.

The device by which an organism maintains itself stationary at a fairly high level of orderliness ... consists in continually sucking orderliness from its environment.

Von Bertalanffy (1968) elaborated and extended this idea.

Living systems are open systems, maintaining themselves in exchange of materials with environment, and in a continuous building up and breaking down of their components....

But in an open system, and especially in a living organism, not only is there entropy production owing to irreversible processes, but the organism feeds, to use an expression of Schrödinger's, from negative entropy, importing complex organic molecules, using their energy, and rendering back the simpler end products to the environment. Thus, living systems, [maintain] themselves in a steady state by the importation of materials rich in free energy.

Arguably, von Bertalanffy was the first to take the next step. He asked what, if anything, do self-sustaining entities have in common? This led him to General System Theory (1972).

Originally von Bertalanffy focused on biological systems. As early as 1928 he wrote,

Since the fundamental character of the living thing is its organization, the customary investigation of the single parts and processes cannot provide a complete explanation of the vital phenomena. The chief task of biology must be to discover the laws of biological systems (at all levels of organization).

One can characterize General System Theory as an attempt to give Aristotle's notion of a form a scientific footing. What organizing principles enable systems to survive and function?

Work in the field blossomed after World War II. von Bertalanffy (19491951) wrote that one must maintain a system-level view while not giving in to the mysticism of holism.

Biology, psychology, sociology and other sciences generally acknowledge the central position of the concept of wholeness. What

1 One often sees both General System Theory and General Systems Theory. Von Bertalanffy favored the singular, but he didn't object to the plural. 
is meant by this concept is indicated by expressions such as system, gestalt, organism, interaction, the whole is more than the sum of its parts, and the like. These concepts have often been misused and are of a vague and somewhat mystical character. General System Theory attempts to formulate these concepts in an exact language.

Soon, others began publishing in the field. Attempting to integrate general system theory with the then-popular quasi-discipline of cybernetics, Ashby (1957), wrote:

Cybernetics offers a method for the scientific treatment of systems in which [a system's very complexity] is too important to be ignored.

Rapoport and Horvath (1959) proposed the notion of "organized complexity," situated between "organized simplicity" and "chaotic complexity"anticipating the notion of complexity as residing at the edge of chaos. Simon (1962) proposed an early definition of complex system.

A complex system consists of a large number of parts that interact in a non-simple way. In such systems, the whole is more than the sum of the parts, not in an ultimate, metaphysical sense, but in the important pragmatic sense that, given the properties of the parts and the laws of their interaction, it is not a trivial matter to infer the properties of the whole. In the face of complexity, an in-principle reductionist may be at the same time a pragmatic holist.

Schrödinger (1944) asked about linking physics and chemistry to biology.

Present-day physics and chemistry cannot account for what happens within a living organism. All atoms are constantly in motion due to heat. Any lawfulness and orderliness that one might think of is made inoperative by the unceasing heat motion.

How much heat motion? Hoffmann (2012, p. 145) compares it to a car in a windstorm.

Every molecular machine in our bodies is hit by a fast-moving water molecule about every $10^{-13}$ seconds. [The] power input from the random pounding of water molecules is a hundred million times larger than the power output of our machines! [For a windstorm to have the same effect on a car,] the storm would need a wind speed of an astounding seventy thousand miles per hour!

To defend against such disorder, biological organisms continually rebuild and repair themselves. In a review of Maturana and Varela's (1980) autopoiesis, Luisi (2003) argued that all biological organisms have "a semipermeable chemical boundary within which 
they are capable of self-maintenance by self-generation of their components from within."

Although the term autopoiesis has been dismissed as lacking scientific rigor, it may be understood to refer to such self-maintenance activities. Generalizing further, social systems-i.e., groupings of living organisms such as families, packs, corporations, countries, etc.-also hold themselves together. For social systems autopoiesis may be understood as self-maintenance within a self-created social boundary (Luisi, 2014). The boundary may consist of means to determine whether an entity belongs to an organization-e.g., distinctive markings or odor.

Somewhat more controversially, Prigogine developed and popularized the notion of dissipative structures. Typically, a dissipative structure develops in systems of partially constrained materials through which energy is pumped. Prigogine's idea was that systems that remain in a steady state but far from equilibrium develop internal structures as a way to dissipate the energy that flows through them. His "Exploring Complexity” (1987) lays out his overall perspective.

[We] are obliged to acknowledge the existence of stochastic processes if we want to avoid the paradox of referring the variety of natural phenomena to a program printed at the moment of the Big Bang. ...

It appears now that the gap between "simple" and "complex," between "disorder" and "order" is narrower than it was thought before. Complexity is no longer limited to biology or human sciences: It is invading the physical sciences and appears deeply rooted in the laws of nature. The basic characteristics of complexity are irreversibility and stochasticity.

For a long time, the interest of thermodynamics concentrated on isolated systems at equilibrium. Today, interest has shifted to non-equilibrium, to systems interacting with their surroundings through an entropy flow. This interaction means that we are dealing with "embedded" systems [such as] towns or living systems, which can only survive because of their embedding in their environment.

There is [a] basic difference with classical mechanics in which the world appears as a museum that conserves everything, including information. The world of thermodynamics is a world of processes, destroying and creating information. Think of the evolution of temperature, the inhomogeneity of which disappears without leaving any trace.

Prigogine is known in some circles as "the poet of thermodynamics." He was awarded the 1977 Nobel Prize in Chemistry "for his contributions to non-equilibrium thermodynamics, particularly the theory of dissipative 
structures." Yet Anderson and Stein (1987) argue that

dissipative structures in real, physical, open systems unconstrained by artificial boundaries will be chaotic and unstable and are not well suited for the production of stable emergent activity.

Another concern is that biological organisms "choose" when and how to import and use energy. Dissipative structures make no such "choices." Energy is pushed through them.

\subsection{Agents and Evolutionary Processes}

The goal of understanding complex systems remained elusive. Little progress was made until 1984 when the founding of the Santa Fe Institute re-energized the field (see German, 2018).

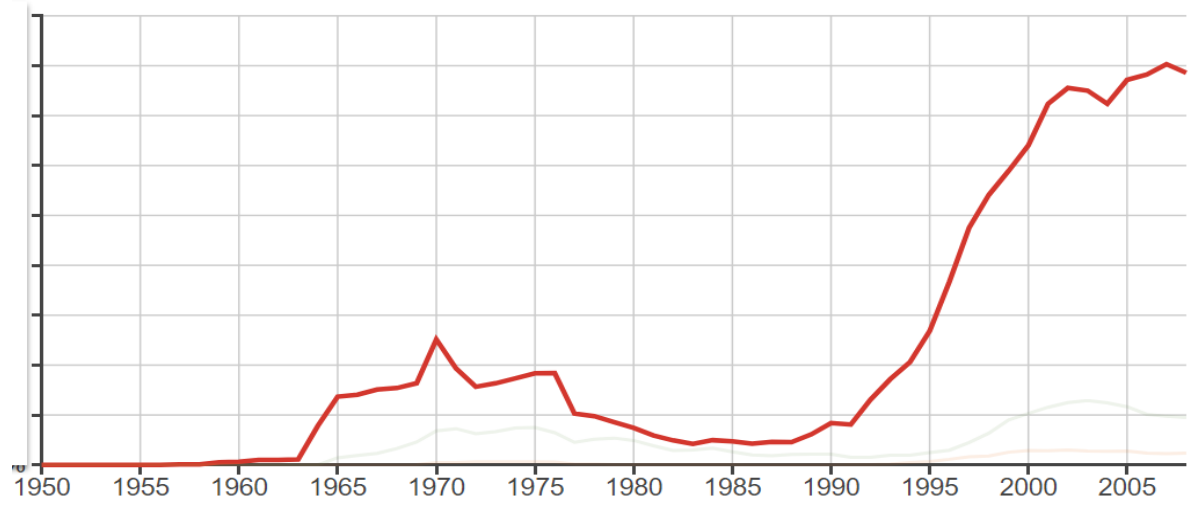

Figure 1. Frequency of appearance of complex adaptive system in published books. The vertical axis shows the percentage of books in which the term appears-starting at $0 \%$. The raw numbers are not of interest. What matters are the relative values. The Ngram search looked for complex adaptive systems. The term complex system is so generic that it appears in contexts that are not about the sorts of complex systems we are discussing.

Figure 1 shows a Google Ngram plot of the appearances of complex adaptive system in published books. An early peak appears two years after von Bertalanffy's summary work (1968) followed by a rebirth due to the Santa Fe Institute (SFI). Ngram data goes only through 2008. Manual searches suggest that usage continued to grow through 2012 but has since declined.

The Santa Fe Institute created an interest in adaptation, and more generally in evolutionary processes. John Holland's genetic algorithm (1975, 1992) lays out a straightforward approach to applying the insights of evolution to a wide range of problems. The genetic algorithm and its derivatives have become widely-used approaches to problems with very large search spaces, and Holland's ideas were incorporated into the SFI view of complex adaptive systems. 
Viewing complex systems through an evolutionary lens brings insight to phenomena that are otherwise difficult to understand. Arthur explains (2015a, 2015b) how an evolutionary perspective changes the way one thinks about economics.

The behaviors of individual agents produce system-level patterns. The agents respond to those patterns by altering their individual behaviors. The altered behaviors produce changed patterns, etc. We need to see social and economic systems ... as a web of incentives that always induce further behavior.

One of the best known agentbased example is Prisoner's Dilemma. Two agents chose, privately, whether to cooperate with or to defect on each other. The payoffs are so arranged that mutual defection leads to meager but positive results for both agents. Mutual cooperation produces better results for both agents. The catch is that if one agent cooperates and the other defects, the cooperator does worse than mutual defection while the defector does better than mutual cooperation. In such an environment defection is the only rational choice.

In what is known as Iterated Prisoner's Dilemma, agents interact multiple times. The best possible result would be achieved by an agent that repeatedly defects against a continually cooperating partner. But in environments in which such "sucker" partners are eliminated by evolutionary pressure, always-defect is not an effective long term strategy. The best feasible strategy is for agents to cooperate with cooperating partners-even though there is no mechanism for making promises about future behavior.

\subsection{Review So Far}

So far, we have seen complex systems come into focus in a number of ways.

1. Aristotle observed that a system has different properties from an aggregation of its components. This typically occurs when component organization makes a difference.

2. Mill and others observed that even when components are put together in well thought-out ways, it seems unlikely that one can construct a living system.

3. The British emergentists suggested thinking in terms of layers in which higher levels are developed from elements of lower levels.

4. Schrödinger, von Bertalanffy, Maturana, and Prigogine observed that biological organisms-and hence complex systems in general-must be open to their surroundings. They import energy and materials and export waste energy and materials.

5. The Santa Fe Institute added a focus on agents and adaptation. Systems consist of individual agents, each of which is capable of pursuing its own ends. The combination of these individual activities produces macro-scale patterns. Agents may observe the patterns they created and 
modify their behavior to achieve better results. Such adaptations may change the macro patterns, leading to further adaptations, etc.

Even given these insights, most complexity scholars agree that there is no standard definition for a complex system. But many mutually consistent characterizations-if not definitionshave been proposed. Recent characterizations follow Simon's lead. A complex system consists of:

- large networks of components, lacking central control, that give rise to complex collective behavior by following simple rules of operations.-Mitchell (2009)

- many interacting parts whose collective behavior is more than the sum of the individual behaviors.Newman (2011)

- an ensemble of many elements, which are interacting in a disordered way, resulting in robust organization and memory.-Ladyman, Lambert, and Wiesner (2013)

- a number of components that interact in such a way that it is difficult to determine, ex ante, by simply concentrating on the components, what the aggregate behavior of the overall system will be.-Axtell et al. (2016)

- many interacting parts that produce collective behaviors that exceed and even transcend the capabilities of the constituents.-Center for the Study of Complex Systems, U. Mich. (2017)
- systems in which many agents interact and adapt to one another and their environments. These interactions and adaptations result in evolutionary processes and often surprising "emergent" behaviors at the macro level.-Santa Fe Institute website (2018b)

Common to the above is the observation that when many elements interact the result is often not easily predictable. One contributing factor, known as disproportionate causality, involves situations in which a system's response to a stimulus dwarfs the stimulus itself. Section 3 explores this area. Section 4 discusses emergence, interactions among many elements that produce macro patterns. Section 5 generalizes the notion of stigmergy, i.e., communication through traces left in the environment. Each contributes to complexity in its own way.

\section{Disproportionate Causality}

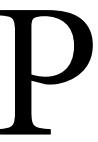
oli (2017) suggests a "golden rule" for distinguishing between (a) complex problems and systems and (b) problems and systems that are merely complicated.

Complicated problems [and systems] originate from causes that can be individually distinguished; ... for each input to the system there is a proportionate output. ... On the other hand, complex problems and systems result from networks of multiple interacting causes that cannot be individually distinguished; ... small inputs may 
result in disproportionate effects. [Emphasis added]

This section discusses three categories of disproportionate causality: tipping points, switches, and symbolic effects. It also discusses the enabling mechanism: energy storage and accessibility.

\subsection{Macro Tipping Points}

Lamberson and Page (2012) define a tipping point as "a discontinuity between current and future states of a system."
A direct tip occurs when a gradual change in the value of a variable leads to a [discontinuous] jump in that same variable in the future. A contextual tip occurs when a gradual change in one variable leads to a discontinuous jump in another.

The Fire Model (Wilensky, 1997) packaged with NetLogo (Wilensky, 1999) explores the effect of tree density on the spread of fires. If a fire starts at the left edge of the forest (see Figure 2), how much of the forest will it destroy?

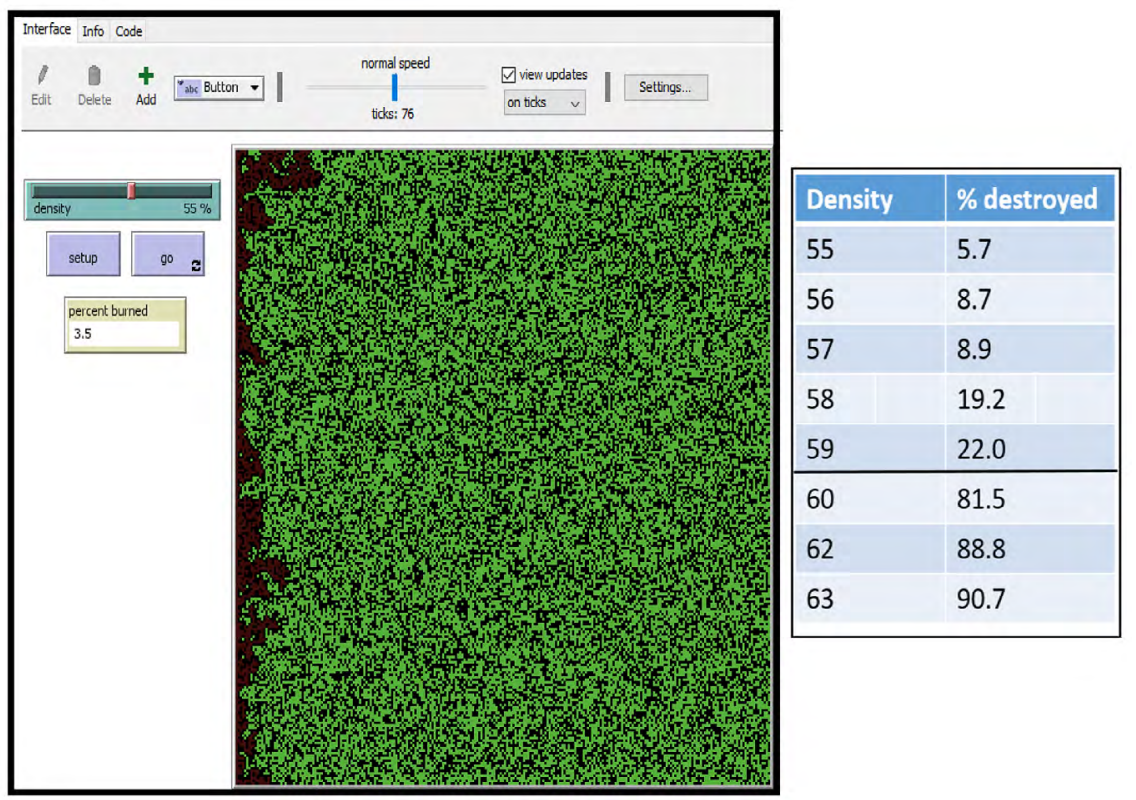

Figure 2. The NetLogo Fire Model.

The NetLogo Behavior Space exploration tool allows one to run a model with different values of the driving variables-density in this case. When applied to the Fire Model, the tool produced the results in Figure 2. There is a contextual tipping point between density values 59 and 60 .

Tipping points frequently mark a boundary between attractor states. The attractors in the fire model are (a) the fire burns out relatively quickly 
and (b) the fire spreads to most of the forest.

Climate change is pushing the world toward a catastrophic tipping point (Spooner, 2018).

The [Atlantic meridional overturning circulation (AMOC)] is like a giant conveyor belt of water. It transports warm, salty water to the north Atlantic where it gets very cold and sinks. Once in the deep ocean the water flows back southwards and then all around the world's oceans. This conveyor belt includes the Gulf Stream and is one of the most important transporters of heat in the climate system.

Caesar, Rahmstorf, Robinson, Feulner, and Saba (2018) reports on recent findings.

[The AMOC] is a highly nonlinear system with a critical threshold. ... In recent years the AMOC appears to have reached a record low, [an unprecedented event in the past millennium]....

Continued global warming is likely to further weaken the AMOC, via changes to the hydrological cycle, sea-ice loss, and accelerated melting of the Greenland Ice Sheet.

Rahmstorf, one of the investigators, explains the concern (Carrington, 2018).

We don't know where [the AMOC] tipping point is and should avoid disrupting it at all costs.

To conclude this section, I would like to discuss a case in which the violation of a tipping point was at least partly corrected. During the early-twentieth-century wolves were eliminated from Yellowstone park. As reported by Kuhne (2018) their disappearance allowed the elk population to explode. Since elk browse on willows, the additional elk reduced the number of willows, the food source for the beaver, causing those animal to abandon smaller streams.

The loss of beaver ponds ... lowered water tables and compressed the area of bare, moist substrate needed for willow establishment. ... Thus, the loss of wolves ... caused multiple changes in the ecosystem's biological and physical processes, creating an alternative state where herbaceous vegetation dominated riparian corridors, where willows were predominately sparse in distribution and short in stature, and where beaver, once abundant, were absent.-Marshall, Thompson Hobbs, and Cooper (2013)

In 1995 and 1996, 31 Canadian wolves were reintroduced to Yellowstone (Phillips \& Smith, 1997). During the following decade, the wolf population shot up to about 170 and then declined to about 100. During the same period, the elk population declined from about 19,000 to about 5,000. These are now stable and sustainable popu- 
lations (Smith et al., 2016). However, the prior elimination of the wolves had pushed the system into a different attractor, which turned out to be resilient (strange use of that word in this context) to wolf restoration. Beavers have not returned to their previous population level, and willows are not as tall as they were before wolves were eliminated (Marshall et al., 2013). So this story is only a partial success.

\subsection{Everyday Tipping Points: Switches and Other Control Mechanisms}

If the tipping points discussed above represent dramatic ecological transitions, the world familiar to most people includes many quotidian tipping points. The triggering of these familiar tipping points is essential both to our survival as biological organisms and to the smooth running of society. They all reflect disproportionate causality. This section examines some familiar examples of disproportionate causality: control systems and switches.

A control system allows one to control the operation of a device or process through the expenditure of minimal amounts of energy. Think of a car with power steering. Turn the steering wheel, and the car changes direction. Consider how much energy would be required to change a car's direction if the only option were the application of a force to one side or another. So a car with power steering produces a significant effect with minimal causal input.

Gene switches provide an interesting example of a control system in nature. Briefly, genes are sequences of DNA that code (indirectly) for proteins. To produce the protein associated with a gene, RNA polymerase binds to the DNA at a location known as a promoter, which is near the start of the gene. It then transcribes the gene to produce messenger-RNA (mRNA), which is decoded by ribosomes to produce the associated protein.

Between each promoter and the gene sits another sequence of DNA known as an operator. When a repressor binds to an operator it blocks RNA polymerase from transcribing the genetic DNA and switches off the production of the protein. This is a gene switch.

Gene switches are vital to biological organisms. They provide a means for organs to manufacture the proteins needed for their own functioning and make it possible for some cells to become eyes while others become feet.

Perhaps an even more striking example of disproportionate causality is the everyday switch. Imagine a switch that controls, say, an electric light. Turn the switch to the on setting, and the light goes on; turn it to the off setting, and the light goes off. The amount of energy required to move the switch from on to off can be minimal. Yet the effect can be arbitrarily large, depending on what the switch controls. The switch is the prototypical example of disproportionate causality.

Of course switches are also important in another context: computing. The transistor is essentially a switch. In computing, switches matter not because of their disproportionality effect 
but because they can be organized to control each other.

\subsection{Sources of Easily Accessible Energy}

Switches involve two energy sources. One flips the switch; the other is the energy flow the switch controls. Switches can exist only if there are such energy flows.

To explain energy flows, we start with a brief overview of our planetary energy flows. The earth as a whole is an open system. It receives energy from the sun. Most of the energy used on earth is solar energy captured via photosynthesis. The average rate of energy capture by photosynthesis is about three times the power consumption of civilization.

Besides energy captured by photosynthesis, we capture solar energy in the form of wind energy, hydroelectric energy, and biomass energy. We also capture solar energy with solar technologies. Non-solar energy sources include geothermal energy and wave and tidal energy.

Whatever its source, energy is generally stored before it is used. Energy captured by photosynthesis is stored initially as glucose. Energy from other sources is either already stored, e.g., as fossil fuels, or is stored in other ways. To be useful, an energy store must release energy on demand. By definition, an easily tapped store of energy can release more energy than is required to trigger it and represents potential disproportionate causality.

Triggering mechanisms make energy stores possible. Without a trigger- ing mechanism, a putative energy store would release its energy spontaneously-and would not be a useful store.

In short, energy is received from the sun and converted to more stable forms for storage. Stored energy is accessed and released as needed for life processes or for other uses such as transportation, manufacturing, household needs, computation, etc.

We live in a world with myriad energy stores. Each biological organism, human beings included, is such a store. Technology provides others such as batteries and fuels.

The existence of many energy stores creates the possibility of chain reactions. Explosion chain reactions of are all too familiar-and we do our best to protect against them. But we are less successful controlling other chain reactions. Examples include a crowd becoming a mob, an online message "going viral," a style becoming a fad, or public opinion swinging to a "strongman" in response to a terrorist threat. Governmental structures, such as a constitution and separation of powers, help throttle such chain reactions. But they do not always succeed. Systems with many easily tapped stores of energy are of necessity less stable and more complex.

\subsection{Symbolic Causes and Autonomous Causality}

The preceding sections discussed disproportionate causality in situations in which the cause was perhaps physically quite small. This section explores symbolic causality. 
Pearl (2000) and Woodward (2003) independently defined what is called interventionist causality, a formalization of the intuition that if wiggling $X$ results in $Y$ wiggling, then $X$ has a causal relationship to $Y$. Unlike physical causality (Dowe, 2000) -in which a physical quantity, such as momentum, is transferred from cause to effect (think one billiard ball hitting another)-interventionist causality does not require such a transfer. Consider our light switch example. The causal mechanism is clear-a switch controls an energy flow-but no physical quantity is transmitted from the agent that flipped the switch to the light.

Symbolic causes are even further removed from direct physical causality. A traffic light changing color causes cars to start/stop. The color change is a symbolic cause.

Following are the primary properties of symbols.

i. Symbols are abstract, and by definition, causally inefficacious (Rosen, 2014).

ii. Symbols have no intrinsic properties. Interchanging symbols in a mathematical or logical argument has no formal consequences.

iii. A symbol's only property is that it can be distinguished from other symbols.

How can an abstract and causally inefficacious symbol be a cause? A symbol produces an effect only when the element on the "effect side" of the relationship attaches a meaning to the symbol-e.g., a car's driver attaches a meaning to a traffic light's color. To connect a symbolic cause to a physical effect requires an interpreter to transform a symbol into physical action. The agent that responds to the symbol determines the effect. I call this autonomous causation (Abbott, 2018).

Notice how extraordinary this is. Laplace (1814) famously wrote (emphasis added),

The present state of the universe is the effect of its past and the cause of its future.

Laplace was talking about the laws of physics. Laplacian causality leaves no room for symbolic causes: you don't expect a rock to respond to a traffic light. Instead of the laws of physics pushing the world around, autonomous agents "choose" how to respond to symbols.

This doesn't negate the laws of physics. It simply establishes two sources of causation. For example, walking uphill involves both the force of gravity and a decision to walk against that force. This sort of two-pronged causality typifies autonomy.

Nor is it an argument for dualism. It is a recognition that the forces at play in the informational world are typically small compared to those at play in the physical world.

When a driver, human or autonomous, sees a traffic light, she (it) converts the photons to a symbol: RedLight or GreenLight. She (it) responds to that symbol by pressing the brake or accelerator, which causes her (its) vehicle to act 
in the world. In purely physical terms, the photons from the light caused the car to stop or go-an extreme case of disproportionate causality.

Dual causality makes unraveling the causes of an autonomous agents' actions potentially quite difficult. What do we know about how an agent will choose to behave? In the case of human agents, we may not know very much. A person's response to a symbol depends on both her inborn decision-making processes and how experience, including schooling, modified those decision-making processes. Without a person's history, her response to a symbol may be undiscoverable except by giving her the symbol and watching what she does.

Notice how different this is from physical causality. When one object is struck by another, the struck object receives transmitted momentum and reacts as expected. It has no choice in the matter. When an agent is "struck" by a symbol it is up to the agent how to respond. (Not stopping at a red light has consequences, but it is still up to the agent.)

Even knowing an agent's decision-making processes doesn't necessarily mean that one knows how the agent will behave. Consider AlphaGo, the computer program that beat the world Go champion (Moyer, 2016; Silver et al., 2016.) We know exactly how it was programed, how it was trained, and the process it uses to select a move. Yet no one is able to predict its moves except by running the program. After all, it picks better moves than anyone else.

The lesson is that difficult as it may be to predict the behavior of some physical systems-because of chaos, attractors, tipping points, etc.-predicting the behavior of autonomous agents is more difficult still. Systems that include interactions among autonomous agents are often quite resistant to predictions about how they will play out.

\section{Emergence}

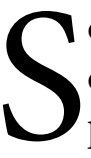
o far we have examined the history of complex systems and how disproportionate causality contributes to complexity. This section looks at phenomena often labeled emergent.

There tend to be two lines of thought about how broad a view to take of emergence.

\subsection{Emergence Involves Autonomous Agents}

This perspective focuses on autonomous agents and their interactions. Refer back to the characterizations of complex systems at the end of Section 2. In those and similar examples, the agents are typically either humans or biological organisms-as, for example, in flocking. They are considered autonomous because each agent determines for itself how it will act. It makes that determination based on its environment and on the actions of its neighbors. Autonomy is understood as the ability of an agent to decide for itself how to act: it is self-governing.

\subsection{Emergence Includes the Interaction of Entities in Purely Non-Symbolic Ways}

An alternative is to take a broader view. Recall the Santa Fe Institute obituary 
for David Pines. For Pines emergence does not require autonomous agents. Interacting elementary particles may produce emergence. Pines (2014) elaborated his position.

When electrons or atoms or individuals or societies interact with one another or their environment, the collective behavior of the whole is different from that of its parts. We call this resulting behavior emergent. Emergence thus refers to collective phenomena or behaviors in complex adaptive systems that are not present in their individual parts. [emphasis added]

Examples of emergent behavior are everywhere, from birds flocking, fireflies synchronizing, ants colonizing, fish schooling, individuals self-organizing into neighborhoods in cities-all with no leaders or central control-to the Big Bang, the formation of galaxies and stars and planets, the evolution of life on earth from its origins until now, the folding of proteins, the assembly of cells, the crystallization of atoms in a liquid, the superconductivity of electrons in some metals, the changing global climate, or the development of consciousness in an infant. [emphasis added]

O'Connor (2015) sketches a similarly broad position.

Emergence is a notorious philosophical term of art. ... We might roughly characterize the shared meaning thus: emergent entities (properties or substances) "arise" out of more fundamental entities and yet are "novel" or "irreducible" with respect to them.

Anderson also takes a broad view of emergence. In his celebrated "More is Different" (1972), he applies the notion of emergence, if not the word itself, to elementary particles.

The behavior of large and complex aggregates of elementary particles ... is not to be understood in terms of a simple extrapolation of the properties of a few particles. Instead, at each level of complexity, entirely new properties appear. ... The whole becomes not merely more, but very different from the sum of its parts. [emphasis added]

Also with elementary particles in mind, Stein and Newman (2013) associate emergence with behaviors such as phase transitions, which are not predictable at the level of individual particles. They note in addition that since salt is not a complex system but does exhibit this sort of abrupt phase transition, emergence is not confined to complex systems.

\subsection{Reconciling These Perspectives}

These perspectives can be reconciled by generalizing the notion of autonomy. Barandiaran, Di Paolo, and Rohde (2009) define agent in a way that allows a bacterium to be an agent. 
An agent is an autonomous organization capable of adaptively regulating its coupling with the environment according to the norms established by its own viability conditions.

I suggest a similar definition but without the viability conditions. To explain, I'll first present a cartoon version of spin glasses (adapted from Stein and Newman).

Imagine a surface in which tops are fixed to the corners of a square. Each top may set its spin to be either clockwise or counter-clockwise. In Figure 3, three of the tops are spinning clockwise. The spin of the fourth is shown as unknown. If this were a simulation, each top would be able to set (or reverse) its spin once each time step.

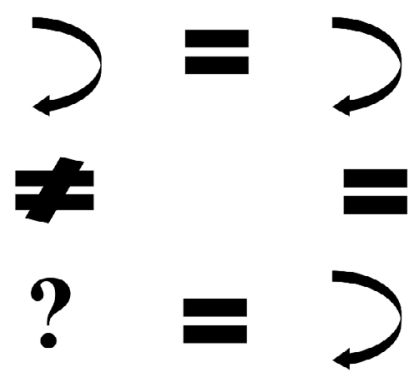

Figure 3. A cartoon spin glass example.

Suppose the surface imposes constraints requiring some spins to align, indicated by the = sign, and some to be opposite each other, which I'll call anti-align, indicated by the $\neq$ sign. In Figure 3, three of the spins (top left, top right, and bottom right) must align.

Given these constraints, there is no way for the lower left top to select a spin that will satisfy all the constraints.
The problem is that it must align with the lower right top and anti-align with the top at the upper left. But the tops at the lower right and upper left must each align with the top at the upper right, which requires that they align with each other. So this set of constraints cannot all be satisfied at once. That's true even if some or all of the tops flip their spins.

How does this relate to autonomy? Each top is autonomous in the sense that it has a choice-in some sense-about whether to spin clockwise or counter-clockwise.

Certainly this is a minimal level of autonomy. But it's not very different from the level of autonomy of flocking boids (Reynolds, 1987). Each boid has the ability to change its velocity by a small amount at each time step. That level of autonomy seems comparable to the ability to flip one's spin. So although each top represents a relatively primitive physical entity, it has sufficient autonomy to adjust its coupling with its environment.

The same holds for other examples in which interactions among relatively elementary entities produce emergent results. Although the entities may be limited in their capabilities, each couples with its environment according to internal rules, which it follows independently. These internal self-directing rules make these entities self-governing, i.e., autonomous.

Spin glasses are relevant to the study of complex systems in that, among other things, complex systems tend to have partially incompatible constraints. When a constraint prompts one ele- 
ment to modify how it relates to its environment, that change may lead some of its neighbors to change, which may lead some of their neighbors to change, etc., producing a cascade of changes that may ripple across the entire system. Effects of this sort appear in flocking. When one boid changes course to avoid an obstacle, others act in response, etc. Such effects also appear in Schelling's famous segregation model (1971) and elsewhere.

The conclusion is that autonomy requires little beyond a certain level of internally-driven rule-based behavior. Complex interactions may occur when even simple autonomous entities interact. With this broader view of autonomy, the two versions of emergence no longer conflict.

\subsection{Static Emergence}

Given Pines' view of emergence-in which every galaxy, every solar system, every chemical compound, every biological organism, every ecological system, every social organization, and every engineered object is emergentdoes the term have any meaning left? Abbott (2015) concluded that given its burden of intellectual baggage there is little reason to continue to use it. Yet, the term retains a useful sense. To get at it, this section and the following two examine three categories of emergence: static, dynamic, and adaptive.

Static emergence involves the transformation of one or more physical things into one or more products. Static emergence occurs both in nature and as a result of human effort. Examples include the transformation of sodium and chlorine to salt (natural) and the construction of most engineered artifacts (human). Static emergence tends to occur over a defined and limited time span, which is typically short compared to the lifetime of the resulting product. In most static emergent processes, our interest centers on the products produced. For example, Markvicka, Bartlett, Huang, and Majidi (2018) report on the development of self-healing electronic materials.

In some important cases, though, the focus is on energy. Static emergence is usually exergonic: energy is released. But photosynthesis, also a form of static emergence, is endergonic: energy is captured. Two other energy-related instances of static emergence are also central to modern civilization. The energy that photosynthesis captures is produced on the sun through hydrogen fusion, a static emergent process which converts hydrogen to helium. That conversion releases enormous amounts of energy, which we experience as sunshine. Were it not for that static emergent solar process, photosynthesis would have no energy to capture.

A second class of exergonic static emergent processes are those through which we generate energy for ourselves: nuclear fission and the combustion of fossil fuels. In both cases, we are interested in the energy, but the (by-) products create problems. Some of the products of nuclear fission remain radioactive for many years. Combustion of fossil fuels produces carbon dioxide, which contributes to global warming. 
A process may be exergonic overall even though some of its products store energy. The sequence of reactions that converts ADP to ATP, life's energy currency, is exergonic. But ATP, which results from adding a phosphate group to $\mathrm{ADP}$, has more energy than the ADP and phosphate group from which it is constructed. The additional energy comes from glucose, which is broken down. More energy is released from glucose than is stored in ATP.

Static emergence produces many important products: materials (old and new), chemical compounds (including medicines), and engineered artifacts. It also produces the energy that powers both life on earth and human civilization. In the bigger picture, static emergence creates solar systems and galaxies along with the heavier elements, which are produced in stars.

I find it not useful to apply the term emergence to these processes. They are fairly well understood and don't need the mystification that the term emergence adds.

\subsection{Dynamic Emergence}

Dynamic emergence involves a continuing process that creates-and more importantly maintains-an ongoing entity. Like static emergence, dynamic emergence occurs both in nature and through human effort. Because maintenance requires a continuing supply of energy and materials, dynamic emergence must involve open systems.

Non-biological examples include the earth's weather system and its global network of ocean currents. In these cas- es, energy from the sun, but no materials, is imported. Biological examples include every biological organism as well as biological collectives such as packs, flocks, families, clans, ant and bee colonies, tribes, and ecologies.

One can construct an strikingly long list of social examples. The conceptually simpler cases include geopolitical entities such as neighborhoods, villages, towns, cities, countries, military and trade alliances (such as NATO and NAFTA), and supra-national organizations (such as the European Union, the World Trade Alliance, the World Court, and the United Nations).

Other familiar examples include businesses, universities, academic organizations (such as the Computational Social Science Society of the Americas), ongoing publications (ranging from Paul Krugman's regular column in the New York Times to the Journal for Policy and Complex Systems), and religious organizations (ranging from the local to the transnational).

Other examples include clubs (such as private golf clubs and bowling leagues), online communities, and musical groups (the Postmodern Jukebox to the Los Angeles Master Chorale).

The political realm teems with dynamically emergent entities: political parties, legislative caucuses (such as the House Climate Solutions Caucus and the House Freedom Caucus), and political and social advocacy groups and movements (such as the ACLU, The Electronic Frontier Foundation (EFF), the Black Lives Matter Global Network, and the Southern Policy Law Center), 
and lobbying associations (such as the AARP, the Pharmaceutical Research and Manufacturing Association, and the National Rifle Association).

Still other groups include service organizations (such as the PTA, Planned Parenthood, Doctors without Borders, and the League of Women Voters), and mutual support and educational organizations (such as Alcoholics anonymous, the American Association of Individual Investors, and the National Alliance on Mental Illness).

As the preceding suggest, dynamically emergent entities play significant roles in society.

Dynamically emergent entities are autopoietic: they sustain and maintain themselves from within. They must be open systems. Some are well-established; others are evanescent.

Dynamically emergent entity tend to be relatively easy to initiate but more difficult to sustain. Consider biological reproduction, establishing a successful business, or building a social movement. The creation step is almost always easier than maintenance.

Its protean nature explains how dynamic emergence adds complexity to complex systems. But as with static emergence, I see no benefit in applying the term emergence to these processes.

\subsection{Adaptive Emergence}

Adaptive emergence refers to modified or new properties or patterns of behavior that develop either in response to features of the physical, social, economic, or political environment, or sometimes simply as a continuation of ongoing processes, e.g., advances in science. Adaptive emergent properties and patterns are frequently fitness-enhancing in that they often increase the relative fitness-or perceived relative fitness - of the entities that adopt or develop them.

Climate change is a non-biological example of adaptive emergence. It consists of recognizable patterns of meteorological changes that have arisen in response to changes in the earth's surface and atmosphere. Climate change does not enhance the "fitness" of the climate.

Biological evolution, on scales from bacteria to the largest organisms, both rapid and long term, illustrates quintessential adaptive emergence. Biological evolution reflects changes in form and behavior that enhance fitness.

Important as static and dynamic emergence are, adaptive emergence may represent the most powerful of the three categories. It is about change. Here is how I would compare the three.

- Static emergence focusses on fixed, stable, and typically purely physical entities. To the extent that they can be considered systems at all, the products of static emergence are closed systems at equilibrium. Even in our example of the production of glucose through photosynthesis, the product, glucose, is a static entity at equilibrium. To release its energy requires the addition of activation energy.

- Dynamic emergence focusses on entities that must continually renew 
themselves. Entities based on dynamic emergence are open systems and must continually find and import energy and other resources. Dynamically emergent entities can often be understood as agents. They interact with each other and with the environment.

- Adaptive emergence is probably the most important category from a societal perspective. Policy makers respond continually to newly emergent properties and patterns of behavior. At the same time, they must avoid policies that will produce unwanted adaptations.

The rest of this section sketches a few examples of adaptive emergence.

Unintended consequences: using the structure and processes of society for unintended purposes. One of the most widely discussed categories of adaptive emergence is that of unintended consequences. Unintended consequences occur when people or organizations respond to a public policy in unanticipated ways. The response typically helps the person or organization but fails to further-and sometimes even foils-the policy goals.

Freakonomics radio (2012) devoted a show to three examples of unintended consequences.

Cobras in Dehli. To rid Delhi of cobras during the British occupation, the governor offered a bounty. In response, the citizens of Delhi started cobra farms. So, the government ended the boun$t y$, and the farmers released their cobras-producing a cobra problem much worse than the original.

Rats in Hanoi. There is a similar story about rats in Hanoi. The French offered a bounty for rat tails. People started rat farms, cut off the tails, and traded them to the government for the bounty.

Pigs in Ft Benning. Ft. Benning was plagued with feral pigs. The authorities offered to pay for pig tails. Residents bought pig tails from slaughterhouses or pig farmers.

In all three cases, a mechanism intended to solve a problem was exploited for other purposes.

Birth tourism illustrates how people exploit what they see as loopholes in the law. To take advantage of the law that grants citizenship to anyone born in the US or Canada, non-citizen pregnant women arrange to give birth in one of these countries.

Saipan has become a popular US destination. To encourage tourism, the government supported a 2009 change in immigration policy that allows Chinese citizens to enter the US visa free for up to 45 days, more than enough time to have a baby (see Emont, 2017; Mullaney, 2018).

Miami has become a birth-tourism destination for Russians (McFadden, Fitzpatrick, Connor and Schecter, 2018).

Vancouver is the favored Canadian destination. Non-resident moth- 
ers now account for nearly $20 \%$ of all births at Richmond Hospital in British Columbia. See Young (2018) for details.

Tax avoidance schemes also fit into this category.

To SWAT is to make a false report of a crime in progress as a way to lure a police SWAT team to the home of an adversary (Jaffe, 2016). In a recent incident (Criss, Hassan, \& Stapleton, 2017), a SWAT team killed a civilian who had innocently moved his hands toward his waist after answering the door for an unexpected SWAT team visit.

In the preceding examples, people took advantage of government-established structures and processes. The following examples represent more organically emergent phenomena.

Live streaming of video games. The most popular platform is Twitch. On average one million people are watching Twitch streams at any moment (Herrman, 2018).

There are two ways to look at Twitch. Oneis that it's people playing video games and other people watching. The other is that you are playing a game while someone sits on the couch. There's a level of interaction that's just not there in standard media. - Clark (2017)

Players and viewers talk to each other and feel part of a relatively intimate group.

Open source software. Although not a new phenomenon, open source software continues to propel change.
Personal live streaming took off with the development of Open Broadcaster Software (OBS) (https://obsproject. com/). Anyone can download it and start live-streaming.

\section{Last mile and flexible local} transportation. Local transportation is an ongoing urban issue. Attempts to address it include MicroTransit (Vock, 2017), bike sharing, Uber/Lyft, and others. Electric scooter sharing companies have recently sprung up nationwide.

Universal Basic Income (UBI). The idea is discussed with increasing frequency as a way to address both poverty and job loss due to AI and robotics. So far there are no significant successful trials. In fact, Finland recently discontinued a UBI trial (Olli-Nilsson, 2018). But discussions and experimentation continues. The Canadian province of Ontario is currently running a trial UBI program (Bergstein, 2018).

Tracking online activity. Techniques have been developed to track the websites people visit and the products they consider buying. With this information advertisers can place targeted ads in ad space they buy in real time as people move from one website to another.

\section{Privacy features are added to} browsers and apps. In response to having their online activity mined for advertising opportunities people are asking for ways to ensure their privacy. Internet companies respond by offering features that they say enhance privacy and give users more control over what information is collected and how it is used. 
Meta abstractions. A meta-abstraction is a generalizations of similar advances in related fields. Here are three that have emerged in recent years.

- Meta-heuristics (Luke, 2013). Meta-heuristic are a class of general computational techniques for solving optimization problems. They include hill climbing, genetic algorithms, ant colony optimization, swarm optimization, and others.

- Discovery science is the development of methods for discovering scientific knowledge through machine learning, data mining, and big data analysis.

- Category theory is finding increasingly widespread application. One application is Compositionality, which studies how parts compose to create wholes. It is applied to physics, natural language processing, cognitive science, and game theory.

\section{So-called populist and nation-} alist movements have gained strength in many countries around the world. The result is often authoritarian governments with increasingly powerful executives.

Markets exhibit so many adaptive emergent properties that they deserve a section for themselves. This subsection is just an overview.

Soros (2009) used the term reflexivity to refer to markets in which participant actions lead other participant to develop strategies, which, when acted upon, lead to more strategies, more actions, etc. The Santa Fe
Artificial Stock Market (Arthur, Holland, LeBaron, Palmer, \& Tayler, 1997; Palmer, Arthur, Holland, LeBaron and Tayler, 1994), illustrates how reflexivity can produce endogenous bubbles and crashes.

Suppose some automated investors "discover" a trading forecast that says, "A price rise in the last $k$ periods is likely to be followed by a rise in next." Suppose also, some (perhaps the same) investors "discover" a trading forecasts that says, "If the current price is more than $y$ times the fundamental earnings value, expect it to fall." The first strategy causes bubble behavior: If the price rises, investors buy-thus validating it, which may cause a further rise, etc. Eventually this drives the price high enough to trigger the second strategy. Investors sell. The price drops, which switches off the upward forecasts, causing other investors to sell; and a crash ensues. The market becomes an ecology of continually changing forecasts.

Econophysics is the formal study of these and related phenomena. Researchers have established that many markets have common statistical properties, known as stylized facts (see Cont, 2001). Huber and Sornette (2016) claim that "econophysics provides the methods, concepts, and tools to scientifically account for reflexivity."

Bubbles are generally considered undesirable. But Sornette and Janeway 
argue that they often serve a useful societal function.

Bubbles are one of our most constructive collective processes. They lead to extraordinary commitment-beyond what would be justified by a standard cost-benefit analysis.-Sornette (2014)

Janeway $(2013,2015)$ explains why this matters.

Speculation has often occurred around technological innovations, including canals, railroads, electrification, automobiles, aviation, computers, and the Internet. These bubbles eventually burst, causing lots of economic damage. But we still had trains after the 1893 crash, we still use electricity despite the 1929 crash, and we have the Internet, despite the dotcom bubble.

Without the mania of bubbles, unproven yet economically revolutionary technologies may not attract sufficient investment to get off the ground.

As the preceding illustrate, a broad range of phenomena might qualify as adaptive emergence. They reflect changes that may be more or less newsworthy but are not considered abnormal. Virtually all societal states include features people can turn to their advantage. That's how evolution works. It's not clear that applying the term emergence to them as a group enhances understanding. An exchange from the movie Ratatouille (Bird \& Pinkava, 2007) sums it up.
Father: Son, you can't change nature!

Son: Change is nature, dad.

\subsection{Binding Forces, Gateways, and the Creative Constructionist Perspective}

Pines (2014) called emergence "A unifying theme for 21 st century science."

The central task of theoretical physics in our time is no longer to write down the ultimate equations, but rather to catalogue and understand emergent behavior in its many guises, including potentially life itself. [The] physics of the $21^{\text {st }}$ century [must] transition from the science of the past, so intimately linked to reductionism, to the study of complex adaptive matter. ...

In the search for an understanding of emergence, Pines recommended studying

emergent collective patterns and regularities [which are] are the gateways to emergent behavior.

Pines re-emphasized the importance of gateways in his 2016 lecture.

Cataloging and connecting these gateways is a first step toward developing a "Physics of Emergence" that would encompass quantum, classical, and living matter, social, and economic behavior. 
Here I respectfully disagree. I doubt that we will uncover a generalized physics of emergence.

As noted much earlier, Aristotle knew that the way components are organized and bound together helps determine the properties of the resulting whole. So one very important question is: what are nature's binding forces? But we already know the answer. Physics and chemistry tell us how to make statically emergent entities. Dynamically emergent entities are held together by specialized applications of imported energy. The forces are not at issue. It's how the energy is used and how components are organized that matters for the properties of the whole.

Emergence is not a mysterious force or property that appears if things are arranged just right. Emergence reflects a perspective more than anything else. Science is famously analytic: take things apart to see how they work. The flip side is synthesis: put things together to get something new. If science is about analysis, technology is about synthesis. Synthesis (technology) depends on analysis (science). We wouldn't have mobile phones were it not for a long list of scientific discoveries, including quantum mechanics (for transistors), the theory of electromagnetism (for the phone's computer and the communication network), optics (for the phone's camera), astrophysics, relativity (for GPS), and on and on. The more science learns about how nature works, the broader the range of forces and materials available to engineers to put together in new ways. Emergence is the perspective that it is possible to put things together to create new things. We do it with technology. Nature does it through evolution.

Some professions specialize in emergence: engineering and computer science, of course, but also the creative arts and even accounting. Every engineered device and every computer program has new properties. So does every new song, every new novel, every new work of art, and every new tax avoidance scheme. These are all instances of adaptive emergence. Emergence is essentially another word for creativitywith either nature or human beings as the creative element.

Anderson (1972) discussed and dismissed what he called the constructionist hypothesis.

The ability to reduce everything to simple fundamental laws does not imply the ability to start from those laws and reconstruct the universe.

Applied to software, my field, this is undoubtedly true. One can't understand a software system consisting of millions of lines of code by a simple extrapolation of the properties of operations like addition and subtraction. Yet software developers do what Anderson suggests is not possible: construct multi-million-line software systems by combining primitive operations.

How is that possible? Most large systems are composed of components: libraries, frameworks, modules, etc. Each component has both a specification-a description of the functional capabilities it offers-and an implemen- 
tation-how it works. It has become a rule in software design to separate a component's specification from its implementation. This rule allows software developers to construct new functional capabilities one level at a time. At each level one need know only the functions the components perform. One need not know how the primitive operations were put together to create those components.

In the case of software, intelligent design is necessary to get from components at one level to the next higher level of functionality. In nature even intelligence is not necessary. As (Dennett, 2009) said, "competence does not require comprehension." Many kinds of animals have hearts, which work more or less the same way. Once a heart is developed-by trial and error-it can serve as a component for many animals. This constructionist process works very well. See Abbott (2019) for an extended discussion.

To give Pines his due, he may have had in mind the phenomenon that many substances exhibit similar properties during phase transitions, e.g., from gas to liquid. I think this is similar to the phenomenon that hearts in different kinds of animals pump blood in more or less the same way.

Consider this computer science example. Implement a Turing machine using the Game of Life (Rendell, 2002). All the results of the theory of computability suddenly apply. Yet those results are not meaningful at the underlying Game-of-Life level. But with creativity, they can emerge.
Putnam (1975) makes a similar point-but without using the term emergence. He says that the only reasonable way to explain why a square peg (with sides of length $d$ ) won't fit through a round hole (with diameter $d$ ) is that

the board [containing the hole] is rigid, the peg is rigid, and as a matter of geometrical fact, the [diameter of the] hole is smaller than the [diagonal of the] peg.

In other words, with the creativity of human minds, the truths of geometry emerge from the interactions of elementary particles.

Abbott (2015) offers a similar example. A block of steel sinks in water, but when shaped as a bowl it floats. Yet punch holes in the bowl and it no longer floats. Floating emerges from the interaction of water molecules and the organized steel molecules. But like computability and geometry, it is not meaningful at the particle level.

Adaptive emergence is a creative process. I doubt we will find a physics that accounts for it.

\section{Stigmergy: Communication in the Material World}

o far we have reviewed the history
of complex systems and discussed
two important factors: dispropor-
tionate causality and emergence. Two
other (and related) areas that are cen-
tral to complex systems are networks
and communication. Both have been
intensively studied for years. This sec- 
tion does not focus directly on either, but it does explore a somewhat unusual perspective on one of them: communication. The perspective derives from the observation that nearly all communication involves leaving traces in the environment for others to observe.

Grassé (1959) introduced the term stigmergy to refer to the phenomenon that traces insects leave in an environment often stimulate actions by other insects. For social insects, this phenomenon serves a proto-communication-like function. Although referring to it as (intentional) communication strikes me as anthropomorphism, stigmergy provides an important means to coordinate the activities of multiple agents-which makes it directly relevant to complex systems. Ant foraging and termite nest building are widely cited examples.

This section generalizes the notion of stigmergy to virtually all communication, illustrating how communication is necessarily a more complex process than we assume.

\subsection{Stigmergy as a General Coordinating Mechanism}

Heylighen (2016) cites Wikipedia as an example of stigmergy as a coordinating mechanism.

Readers are stimulated to improve and expand the writings of previous contributors. In situations in which subsequent actions are stimulated by the trace left by previous actions, virtually all evolved processes that require coordination rely at some level on stigmergy.

Heylighen also sees stigmergy as underlying the "invisible hand" of markets. After an economic transaction, the trade price, if public, serves as a trace that stimulates further activity.

In both Wikipedia and economic transactions, a common practice is to record not only the activity itself but also the change it reflects. Consider the voluminous history kept about prices and Wikipedia's history pages. The change record itself can serve as an action trigger.

I would extend the reach of stigmergy still further. Consider, for example, intra-organism communication via, say, hormones released into the blood stream. The hormones serve as a trace one organ leaves, which triggers an activity by another.

As another example, consider that when attacked by herbivores the damaged plants release volatile chemicals. Insects that prey on the attacking herbivores can sense those chemicals and follow the trail to their prey. Plants may then evolve better targeted chemicals, which result in more defenders coming to their rescue. The rescuers may also evolve more sharply focused sensing mechanisms. Inter-species stigmergic proto-communication can facilitate evolution.

\subsection{Communication is Almost Never a Non-Stop Journey}

Even more generally, news services and interview shows reflect stigmer- 
gy. They provide an artificial environment in which agents can leave traces for others to observe. Those who provide the information-i.e., newsmakers, entertainers, "guests" on interview shows, etc.-do so with the intention of having those traces observed. These media make explicit what had been implicit: information may be imprinted on the environment for others to observe. Social media such as Facebook, Twitter, Slack, YouTube, etc. extend this functionality to the general public.

Finally, I would categorize as stigmergic all communication mediated by mechanisms that allow a physical record to be recorded at one time and observed at another-any communication not involving direct physical interaction (such as tapping someone on the shoulder). Airport travelers decide which way to turn on seeing signs pointing to "Baggage claim" or "Terminal C."

An important feature of stigmergic communication is that what is recorded is treated symbolically or proto-symbolically by the observer. This enables non-symbols, e.g., insect pheromones or volatile plant chemicals, to function as proto-symbols, e.g., indications of a path to food. Human beings have extended this process to symbolic communication.

Some environments not only record traces, they also act on them and provide services for users. Email messages are traces that are created and then directed to specific targets. Instant messaging systems provide a similar service. Shopping websites make it as convenient as possible for potential customers to create purchase messages to be left for venders. An extraordinary amount of human activity involves communicating through stigmergic systems.

Even software reflects stigmergy. When a programer writes software, she creates traces for a computer to observe and to act on. This indirection makes writing software often surprisingly challenging. It is misleading to say that the computer does exactly what one tells it to do. It is not like driving a car: turn the steering wheel, and the car changes direction. When writing software, one must be aware that what one writes will be read and interpreted by another agent, the computer. As in all the cases discussed, the actions taken by the observer depend on the observer-autonomous causality again-not on the programer's intentions.

The humble programmer can do little more than leave expressions in the path of an oncoming computer and hope that when the computer encounters them it will do as she wishes.

Like fish, which are not aware they are swimming in water, we exist in a shared information environment. We cannot escape leaving traces in our environment. As mentioned in the section on adaptive emergence, tracking systems record the websites we visit and the products we examine. We are like prey being tracked by predators. We would like to make ourselves invisible, 
but our very existence leaves traces in the environment.

We also exploit the fact that the environment can record information. We record information for others to observe-email messages, etc. as mentioned above-as well as for our future selves. Clark and Chalmers (1998) call the latter the extended mind. No one remembers telephone numbers; our "contacts" lists remember them for us.

One societal consequence is the "emergence" of new problems. Many people feel overwhelmed by news and data. The current US president is an expert at manipulating people through tweets. Society has never before encountered these situations and does not know how to respond.

The media that facilitate communication are the original multi-sided platforms (e.g., Hagiu \& Wright, 2015).

\section{Summary}

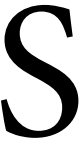
$o$, why are complex systems complex? We presented a brief history of complex systems from Aristotle to the present and found that complexity has many parents.

- To understand a system one must understand not only its component parts, but also their organization and the forces that hold them together.

- A system of any complexity must be open so that it can draw energy and other resources from its environment. Such systems are generally both stable and far from equilibrium.
- Such systems must have means (a) for acquiring those resources, (b) for making use of them to maintain itself, and (c) for eliminating waste products.

- Far-from-equilibrium systems can exist only in an environment of available energy.

- Environments with plentiful energy flows may have critical tipping points.

- Systems that depend on energy usually have means to store and to access it.

- Energy storage mechanisms exhibit disproportionate causality: more energy is released than is required to trigger the release.

- Energy storage mechanisms abound in both the biosphere and human society.

- A world of many easily triggered energy stores opens itself to cascading chain reactions.

- In a world with symbol processing entities-and even proto-symbol processing entities-energy can be released in response to symbols or proto-symbols. This can create nearly unboundedly disproportional effects.

- Emergent phenomena may be classified as static, dynamic, or adaptive. All contribute to complexity.

- Given its quasi-mystical baggage, the term emergence should be retired. 
- Adaptive emergence is a synonym for creativity. Nature, without consciousness, and human beings, with it, continually create new phenomena, thereby adding complexity to the world.

- Other than direct contact, communication is always stigmergic. It is mediated by a physical trace, which subjects it to misinterpretation, to deception, and to third-party observation.

- Stigmergy encourages the development of new environments that enable stigmergic communication. If a new environment becomes widely used it can be very valuable.

\section{References}

Abbott, R. (2015). The end of (traditional) emergence: Introducing reactive emergence. Journal on Policy and Complex Systems, 2(2), 91-107. doi:10.18278/jpcs.2.2.6

Abbott, R. (2018). Meaning, autonomy, symbolic causality, and free will. Review of General Psychology, 22, 85-94. doi:10.1037/gpr0000125. In R. Baumeister (Ed.), Special issue on the meanings of meaning, Review of General Psychology).

Abbott, R. (2019). A software-inspired constructive view of nature. In D. Berkich (Ed.), Computing and philosophy: Selected papers from IACAP 2016.
Anderson, P. W. (1972). More is different. Science, 177(4047), 393-396.

Anderson, P. W., \& Stein, D. L. (1987). Broken symmetry, emergent properties, dissipative structures, life. In F. E. Yates (Ed.), Self-organizing systems (pp. 445-457). New York, NY: Springer .

Aristotle. (350 BCE). Metaphysics, book VIII, 1045a.8-10 (W. D. Ross, Trans.). Retrieved from http://classics.mit.edu/ Aristotle/metaphysics.8.viii.html.

Arthur, W. B. (2015a). Complexity economics: A different framework for economic thought. In Arthur (Ed.), Complexity and the economy (pp. 1-29). Oxford, England: Oxford University Press.

Arthur, W. B. (2015b). All systems will be gamed: Exploitive behavior in economic and social systems. In Arthur (Ed.), Complexity and the economy (pp. 103-118). Oxford, England: University Press.

Arthur, W. B., Holland, J. H., LeBaron, B., Palmer, R., \& Tayler, P. (1997). Asset pricing under endogenous expectations in an artificial stock market. In W. B. Arthur, S. Durlauf, D. Lane (Eds.), The economy as an evolving complex system II. Boston, MA: Addison-Wesley.

Ashby, W. R. (1957). Introduction to cybernetics. London, England: Chapman and Hall.

Axtell, R., Kirman, A., Couzin, I. D., Fricke, D., Hens, T., Hochberg, M. E., 
J. E., P.\& ... Sethi, R. (2016). Challenges of integrating complexity and evolution into economics. In D. S. Wilson \& A. Kirman (Eds.), Complexity and evolution: Toward a new synthesis for economics (pp. 65-81). Cambridge, MA: MIT Press.

Barandiaran, X. E., Di Paolo, E., \& Rohde, M. (2009). Defining agency: Individuality, normativity, asymmetry, and spatio-temporality in action. Adaptive Behavior, 17(5), 367-386.

Bergstein, B. (2018, June 20). Basic income could work-if you do it Canada-style. MIT Technology Review. Retrieved from https://www. technologyreview.com/s/611418/ universal-basic-income-works-if-youdo-it-canada-style/.

Bird, B., \& Pinkava, J. (2007). Ratatouille. Pixar Animation Studios.

Caesar, L., Rahmstorf, S., Robinson, A., Feulner, G., \& Saba, V. (2018). Observed fingerprint of a weakening Atlantic Ocean overturning circulation. $\mathrm{Na}$ ture, 556(7700), 191.

Carrington, D. (2018, April 13). Avoid Ggulf Stream disruption at all costs, scientists warn. The Guardian.

Center for the Study of Complex Systems. (2017). Website, University of Michigan . Retrieved from https://lsa. umich.edu/cscs.

Clark, A., \& Chalmers, D. (1998). The extended mind. Analysis 58(1), 7-19.
Clark, T. (2017, November 20). How to get rich playing video games online. The New Yorker. Retrieved from https://www.newyorker.com/ magazine/2017/11/20/how-to-getrich-playing-video-games-online.

Cont, R. (2001). Empirical properties of asset returns: Stylized facts and statistical issues. Quantitative Finance, 1, 223-236.

Criss, D., Hassan, C., \& Stapleton, A. C. (2017) Police kill a man at his home while responding to a fake call. $\mathrm{CNN}$.

Dennett, D. (2009). Darwin's "strange inversion of reasoning." Proceedings of the National Academy of Sciences Jun 2009, 106(Supplement 1), 1006110065. Retrieved from http:// www.pnas.org/content/pnas/106/ Supplement_1/10061.full.pdf.

Dowe, P. (2000). Physical causation. New York, NY: Cambridge University Press.

Emont, J. (2017). Saipan: The island where Chinese mothers deliver American babies. The Wall Street Journal. Retrieved from https://www. wsj.com/articles/the-island-wherechinese-mothers-deliver-americanbabies-1513852203 .

Fontenelle, B. (1686). Entretiens sur la pluralité des mondes [Conversations on the plurality of worlds].

Fontenelle, B. (1766). Lettres galantes in Oevres. Librares Associes. 
Freakonomics. (2012). The cobra effect. Retrieved from http://freakonomics. com/2012/10/11/the-cobra-effect-fulltranscript/.

Gasser, A. (2003). World's oldest wheel found in Slovenia, Press release from the government communication service, Republic of Slovinia.

German, J. (2018). Something from nothing: SFI emerges and synthesizes. Santa Fe Institute Website. Retrieved from https://www.santafe.edu/about/ history.

Grassé, P. P. (1959). La reconstruction du nid et les coordinations inter-individuelles chez Bellicositermes Natalensis et Cubitermes sp. La théorie de la stigmergie: essai d'interprétation du comportement des termites constructeurs. Insectes Sociaux, 6, 41-81.

Hagiu, A., \& Wright, J. (2015). Multi-sided platforms. International Journal of Industrial Organization, 43, 162-174.

Herrman, J. (2018). With twitch, Amazon tightens grip on live streams of video games. The New York Times . Retrieved from https://www.nytimes. com/2018/06/17/business/media/ amazon-twitch-video-games.html.

Heylighen, F. (2016). Stigmergy as a universal coordination mechanism I: Definition and components. Cognitive Systems Research, 38, 4-13.

Hoffmann, P. (2012). Life's ratchet: How molecular machines extract order from chaos. New York, NY: Basic Books.

Holland, J. H. (1975/1992). Adaptation in natural and artificial systems: An introductory analysis with applications to biology, control, and artificial intelligence. Cambridge, MA: The MIT Press.

Hooke, R. (1665). Micrographia. Lincolnwood, IL: Royal Society.

Huber, T. A., \& Sornette, D. (2016). Can there be a physics of financial markets? Methodological reflections on econophysics. The European Physical Journal Special Topics, 225(17-18), 3187-3210.

Jaffe, E. M. (2016). Swatting: the new cyberbullying frontier after Elonis v. United States. Drake Law Review, 64, 455.

Janeway, W. H. (2013). Bring on the bubble: William Janeway on the future of green technologies. Institute for New Economic Thinking. Retrieved from https://www.ineteconomics. org/perspectives/blog/bring-on-thebubble-william-janeway-on-thefuture-of-green-technologies.

Janeway, W. H. (2015, May 28). Unicorns: Why this bubble is different. Forbes.

Kuhne, M. (2018). Scientists debunk myth that Yellowstone wolves changed entire ecosystem, flow of rivers. AccuWeather. Retrieved from https:// www.accuweather.com/en/weathernews/scientists-debunk-myth-that- 
yellowstone-wolves-changed-entireecosystem-flow-of-rivers/70004699.

Ladyman, J., Lambert, J., \& Wiesner, K. (2013). What is a complex system? European Journal of Philosophy of Science, 3, 33-67.

Lamberson, P. J., \& Page, S. E. (2012). Essay: Tipping points. Quarterly Journal of Political Science, 7(2), 175-208. doi:10.1561/100.00011061

Laplace, P. S. (1814/1951). A philosophical essay on probabilities (F. W. Truscott \& F. L. Emory, Trans.). New York, NY: Dover.

Luisi, P. L. (2003). Autopoiesis: A review and a reappraisal. Naturwissenschaften, 90,49-59. doi:10.1007/s00114-002-0389 $-9$

Luisi, P. L. (2014). The minimal autopoietic unit. Origins of Life and Evolution of Biospheres, 44(4), 335-338.

Luke, S. (2013). Essentials of metaheuristics. Lulu. Retrieved from http://cs.gmu.edu/ sean/book/ metaheuristics/.

Markvicka, E. J., Bartlett, M. D., Huang, X., \& Majidi, C. (2018). An autonomously electrically self-healing liquid metal-elastomer composite for robust soft-matter robotics and electronics. Nature Materials, May 21.

Marshall, K. N., Thompson Hobbs, N., \& Cooper, D. J. (2013). Stream hydrology limits recovery of riparian eco- systems after wolf reintroduction. Proceedings of the. Royal Society B, 280, 20122977. doi:10.1098/rspb.2012.2977

Maturana, H., \& Varela, F. ([1st ed. 1973] 1980). Autopoiesis and cognition: The realization of the living. In S. R., Cohen, \& M. W. Wartofsky (Eds.), Boston studies in the philosophy of science. Boston, MA: Reidel.

McFadden, C., Fitzpatrick, S., Connor, T., \& Schecter, A. R. (2018, January 9). Birth tourism brings Russian baby boom to Miami. NBC News. January Retrieved from https://www. nbcnews.com/news/us-news/birthtourism-brings-russian-baby-boommiami-n836121.

Mill, J. S. (1843). A system of logic: Ratiocinative and inductive. London, England: Parker.

Mitchell, M. (2009). Complexity: A guided tour. New York, NY: Oxford University Press.

Moyer, C. (2016, March 28). How Ggoogle's AalphaGo beat a go world champion. The Atlantic.

Mullaney, J. (2018). The secret island where Chinese mothers go to deliver American babies.

Newman, M. (2011). Complex systems: A survey. American Journal of Physics $79,800-810$.

Nobelprize.org (1997). The 1977 nobel prize in chemistry. Nobel media $A B$ 
2014. Swedish Academy. Retrieved from https://www.nobelprize.org/nobel_ prizes/chemistry/laureates/1977/index. html.

O'Connor, T., \& Wong, H. Y. (2015). Emergent properties, the Sstanford encyclopedia of philosophy (Summer 2015 ed.; E. N. Zalta, Ed.).

Olli-Nilsson, K. (2018, April 19). Finland is killing its experiment with basic income. Business Insider.

Palmer, R.G., Arthur, W. B., Holland, J., LeBaron, B., \& Tayler, P. (1994). Artificial economic life: A simple model of a stock market. Physica D, 75, 264-274.

Pearl, J. (2000). Causality: Models, reasoning and inferences. New York, NY: Cambridge University Press.

Phillips, M. K., \& Smith, D.W. (1997). Yellowstone Wolf project: Biennial report 1995 and 1996. National Park Service, Yellowstone Center for Resources, Yellowstone National Park, Wyoming, YCR-NR-97-4.

Pines, D. (2014). Emergence: A unifying theme for $21^{\text {st }}$ century science. Santa Fe Institute Bull, 28, 22-29. Published in Medium, October 31. Retrieved from https://medium.com/sfi-30foundations-frontiers/emergencea-unifying-theme-for-21st-centuryscience-4324ac0f951e.

Pines, D. (2016, December 12). Gateways to emergent behavior in science and society. Lecture given (remotely from SFI) to the Hong Kong University of Science and Technologyember. Retrieved from https://archives.ust.hk/ dspace/handle/9999/45285.

Poli, R. (2017). Complexity. Introduction to anticipation studies. In R. Poli \& M. Valerio (Eds.), Anticipation Science (Vol. 1) (pp.1-8). New York, NY: Springer.

Prigogine, I. (1987). Exploring complexity. European Journal of Operational Research, 30(1987), 97-103.

Putnam, H. (1975). Philosophy and our mental life. In Mind, language and reality (pp. 291-303). Cambridge, England: Cambridge University Press .

Rapoport, A., \& Horvath, W. (1959). Thoughts on organization theory and a review of two conferences. General Systems, 4, 87-93.

Rendell, P. (2002). Turing universality of the game of life. In Collision-based computing (pp. 513-539). Springer. Retrieved from http://uncomp.uwe.ac.uk/ CAAA2011/Program_files/764-772. pdf.

Reynolds, C. W. (1987). Flocks, herds and schools: A distributed behavioral model. In ACM SIGGRAPH computer graphics (Vol. 21, No. 4, pp. 25-34). ACM.

Rosen, G. (2014). Abstract objects. In E. N. Zalta (Ed .) The Stanford encyclopedia of philosophy. 
Santa Fe Institute website (2018a) In memoriam: David Pines. Retrieved from https://www.santafe.edu/news-center/ news/memoriam-david-pines.

Santa Fe Institute website. (2018b). Retrieved from https://www.santafe.edu/ about.

Schelling, T. C. (1971). Dynamic models of segregation. Journal of mathematical sociology, 1(2), 143-186.

Schrödinger, E. (1944). What is life? Cambridge, England: Cambridge University Press.

Silver, D., Huang, A., Maddison, C. J., Guez, A., Sifre, L., van den Driessche, G., ... Hassabis, D. (2016). Mastering the game of go with deep neural networks and tree search. Nature, 529, 484-489.

Simon, H. A., (1962). The architecture of complexity. Proceedings of the American Philosophical Society, 106(6), 467482.

Smith, D. W., Stahler, D. R., Metz, M., Cassidy, K. A., Stahler, E. E., Almberg, E. A., \& McIntre, R. (2016). Wolf restoration in yellowstone: Reintroduction to recovery. Yellowstone Science, 24(1), 5-11.

Sornette, D. (2014). Physics and financial economics (1776-2014): Puzzles, Ising and agent-based models. Reports on Progress in Physics, 77(6), 062001.

Soros, G. (2009, October 26). General theory of reflexivity. Financial Times.
Spooner, P. T. (2018). Climate change is slowing Atlantic currents that help keep Europe warm. The Conversation. Retrieved from https://theconversation. com/climate-change-is-slowingatlantic-currents-that-help-keepeurope-warm-94930.

Stein, D., \& Newman, C. (2013). Spin glasses and complexity. Woodstock, England: Princeton University Press.

Vock, D. C. (2017, December 11). Beyond the bus: "Microtransit" helps cities expand transportation services. Governing. Retrieved from http://www. governing.com/topics/transportationinfrastructure/gov-transit-agenciesextend-service-with-microtransit.html.

von Bertalanffy, L. (1928/1934). Kritische Theorie der Formbildung [Modern theories of development] (J. H. Woodger, Trans.). Borntraeger/Oxford University Press .

Von Bertalanffy, L. (1949). Das biologische Weltbild. Francke. English translation: Problems of life: An evaluation of modern biological thought. Watts; Wiley, 1952; Harper Torchbooks, 1960.

von Bertalanffy, L. (1950a). An outline of general system theory. The British Journal for the Philosophy of Science, I(2), 134-165.

von Bertalanffy, L. (1950b). The theory of open systems in physics and biology, Science, 111, 23-29.

von Bertalanffy, L. (1951). General sys- 
tem theory, a new approach to unity of science. Chap. 6. Towards a physical theory of organic teleology, feedback and dynamics. Human Biology, 23(4), 346-361.

von Bertalanffy, L. (1968). General system theory. Foundations, development, applications. Braziller. Available as textpdf and other formats. Retrieved from https://ia801608.us.archive.org/31/ items / GeneralSystem Theory/ General\%20System\%20Theory_text. pdf.

von Bertalanffy, L. (1972). The history and status of general systems theory, The Academy of Management Journal, 15(4), 407-426.

Wilensky, U. (1997). NetLogo fire model. Evanston, IL: Center for Connected Learning and Computer-Based Modeling, Northwestern University. Retrieved from http://ccl.northwestern. edu/netlogo/models/Fire.
Wilensky, U. (1999). NetLogo. Evanston, IL: Center for Connected Learning and Computer-Based Modeling, Northwestern University. Retrieved from http://ccl.northwestern.edu/net$\log /$.

Woodward, J. (2003). Making things happen: A theory of causal explanation. Oxford University Press.

Yoshida, S., Hiraga, K., Takehana, T., Taniguchi, I., Yamaji, H., Maeda, Y., ... Oda, K. (2016). A bacterium that degrades and assimilates poly(ethylene terephthalate). Science, 351(6278), 1196 -1199 .

Young, I. (2018). The million-dollar baby and the rise of "birth tourism." New Zealand Herald. Retrieved from https:// www.nzherald.co.nz/world/news/ article.cfm?c_id=2\&objectid= 12070120. 